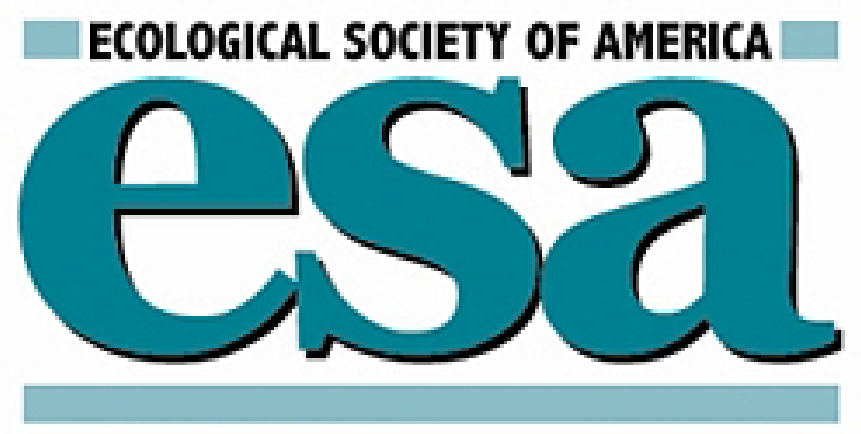

Energy Costs of Subduing and Swallowing Prey for a Lizard

Author(s): F. Harvey Pough and Robin M. Andrews

Source: Ecology, Vol. 66, No. 5 (Oct., 1985), pp. 1525-1533

Published by: Ecological Society of America

Stable URL: http://www.jstor.org/stable/1938015

Accessed: 13/03/2014 09:31

Your use of the JSTOR archive indicates your acceptance of the Terms \& Conditions of Use, available at http://www.jstor.org/page/info/about/policies/terms.jsp

JSTOR is a not-for-profit service that helps scholars, researchers, and students discover, use, and build upon a wide range of content in a trusted digital archive. We use information technology and tools to increase productivity and facilitate new forms of scholarship. For more information about JSTOR, please contact support@jstor.org. 


\title{
ENERGY COSTS OF SUBDUING AND SWALLOWING PREY FOR A LIZARD ${ }^{1}$
}

\author{
F. Harvey Pough \\ Section of Ecology and Systematics, Cornell University, Ithaca, New York 14853-2701 USA \\ AND \\ ROBIN M. ANDREwS \\ Department of Biology, Virginia Polytechnic Institute and State University, \\ Blacksburg, Virginia 24061-0794 USA
}

\begin{abstract}
We measured the oxygen consumption (aerobic energy cost) and lactic acid production (anaerobic energy cost) of scincid lizards, Chalcides ocellatus, eating domestic crickets. Aerobic metabolism accounted for $90 \%$ or more of the total energy cost of subduing and swallowing prey. The time required to subdue and swallow a cricket was linearly correlated with oxygen consumption. Oxygen consumption increased as a power function of cricket mass, but the maximum size of crickets swallowed by the lizards was set by morphological rather than by energetic constraints. The energy cost of subduing and swallowing was $0.2-0.4 \%$ of the utilizable energy of the crickets eaten. Net energy gain per unit time spent subduing and swallowing prey $(e / t)$ declined monotonically with increasing cricket mass. Because the energy cost of eating is trivial, the shape of the $e / t$ curve is determined by the function relating prey mass to the time required for subduing and swallowing; the energy value of prey was proportional to prey mass, whereas the time required for subduing and swallowing increased faster than prey mass. The energy value of arthropods is so high, relative to the costs for a lizard of pursuing, subduing, and swallowing, that these costs can be ignored for most ecological purposes.
\end{abstract}

Key words: Chalcides ocellatus; ecological models; energetics; energy budget; glycolysis; lizards; optimal foraging; oxygen consumption; predation; Scincidae.

\section{INTRODUCTION}

Many predators pursue prey over relatively short distances and swallow their prey whole. The net energy value of each prey item is thus the difference between its utilizable energy and the energy cost of pursuit, subduing, and swallowing. The energy costs of subduing and swallowing can be isolated in this relationship when the energy costs of pursuit are relatively small (see Discussion). Under these conditions, a fundamental question is whether the energy costs of subduing and swallowing make certain prey sizes unprofitable for a particular predator.

One important assumption of several theoretical models is that the optimal diet is found by maximizing the net energy gained per unit time spent feeding. Basic to such models is the quantity $e / t$, where $e$ is the net energy yield of the prey and $t$ is the time required to subdue and swallow it. The model that deals most explicitly with this aspect of predatory behavior is that of Schoener $(1969,1979)$. In this model, a predator feeds optimally by eating prey with larger values of $e / t$; i.e., all prey eaten have larger $e / t$ than all prey not eaten. Moreover, as prey size increases, the $e / t$ function should decline because the gross energy value of the prey is eventually counterbalanced by the energy costs of subduing and swallowing that prey. This relationship suggests that some potential prey items will not be eaten because costs of subduing and swallowing make them

\footnotetext{
${ }^{1}$ Manuscript received 12 July 1984; revised 4 December 1984; accepted 6 December 1984.
}

unprofitable for the predator. The $e / t$ function may also decline as prey size decreases if $t$ is constant at small prey sizes.

The prediction that short-term energy requirements may set the upper limit to prey size has been made from other considerations. Recent studies of the physiological ecology of amphibians and reptiles suggest that the source of the energy used during a predatory encounter might have greater consequences for the cost of subduing and swallowing than the absolute amount of energy used (Bennett 1982, Taigen et al. 1982). In laboratory experiments, amphibians and reptiles support low levels of activity with aerobic metabolism, but greater effort is sustained in part by anaerobic metabolism. At maximum activity, half or more of the ATP is derived from glycolysis (Bennett 1982, Taigen and Pough 1985). Limited data suggest that anaerobic metabolism is used in some natural situations (Bennett et al. 1981, Feder and Arnold 1982, Ryan et al. 1983, Pough and Gatten 1984, Pough and Andrews 1985). An animal that used substantial anaerobic energy input to subdue prey would experience costs that are qualitatively different from those resulting from activity that can be supported entirely by aerobic metabolism. A stoichiometric relationship exists between depletion of glycogen and accumulation of lactic acid in the muscles of the lizard Sceloporus occidentalis during forced activity. Replenishment of muscle glycogen stores required $2.5 \mathrm{~h}$ at $35^{\circ} \mathrm{C}$ (Gleeson 1982). Depletion of muscle glycogen reduces muscular strength and endurance and limits the additional use of anaerobic glycolysis 
(Putnam 1979a, b). Thus, the consequences of using anaerobic metabolism might extend well beyond the few minutes actually involved in a predatory event. A lizard that relied extensively upon anaerobic glycolysis to capture and subdue prey might find its subsequent behavior limited for a substantial portion of its daily activity period. If that is the case, the maximum size of prey that a lizard will attack might correspond to the largest item that can be subdued and consumed without anaerobic glycolysis extending to the point of impaired performance. In combination, these two relationships suggest there is a prey size at which $e / t$ is maximal.

Both of these lines of reasoning suggest that shortterm energy relationships set a maximum size for prey that should be attacked. On the other hand, the few studies that have considered the net value of prey relative to a predator's long-term energy budget have concluded that "bigger is better" and that the largest item that can be swallowed should be eaten (Feder and Arnold 1982, Sherry and McDade 1982). Unfortunately, empirical information about the costs of subduing and swallowing prey is limited and incomplete. For example, Feder and Arnold (1982) measured the anaerobic (but not the aerobic) cost for a garter snake of subduing and swallowing salamanders, Pough and Andrews (1985) measured only the anaerobic cost of feeding by free-ranging lizards, and Sherry and McDade (1982) measured the time (but not the energy) that two species of birds spent subduing insects.

The object of our study was to measure time and energy (aerobic and anaerobic) costs of subduing and swallowing insect prey by a lizard predator. The predator used was the skink Chalcides ocellatus. This species is widely distributed in northern Africa (Pasteur 1981). It is characterized by an elongated trunk and somewhat reduced limbs that are adaptations for a semi-fossorial life style. The prey was domestic crickets, Acheata domestica. Our results provide comprehensive information about the total time and energy costs of subduing and swallowing prey.

\section{Materials AND Methods \\ Experimental animals}

Experiments were conducted with 21 juvenile Chalcides ocellatus (Scincidae). These individuals were the offspring of adults shipped to Blacksburg, Virginia, from Egypt in July 1981. The lizards were kept in terraria with sand in which they could bury themselves. They were fed domestic crickets of various sizes, cockroaches, and mealworms, with supplementary vitamins and calcium. The lizards were exposed to the local photoperiod throughout the year, and heat lamps allowed them to thermoregulate for $6 \mathrm{~h}$ daily. The lizards maintained body temperatures between $32^{\circ}$ and $36^{\circ} \mathrm{C}(\bar{X}=$ $34.4^{\circ}, n=13$ measurements) as they moved about the surface of the sand.
The lizards were divided into two classes for statistical purposes. The smaller lizards had a mean mass of $5.1 \mathrm{~g}$ (range: $4.3-6.2 \mathrm{~g}$ ), a mean snout-vent length (SVL) of $70.4 \mathrm{~mm}(66-75 \mathrm{~mm})$, and a mean jaw length of $10.1 \mathrm{~mm}(9.9-10.4 \mathrm{~mm})$. The larger lizards had a mean mass of $7.6 \mathrm{~g}(6.3-9.1 \mathrm{~g})$, a mean SVL of 79.2 $\mathrm{mm}(77-85 \mathrm{~mm})$, and a mean jaw length of $11.1 \mathrm{~mm}$ $(10.5-12.0 \mathrm{~mm})$. Because the lizards regularly ingested sand, body masses were measured after the lizards had been kept for $72 \mathrm{~h}$, unfed, in sand-free cages. Jaw length was measured as the linear distance from the mandibular symphysis to the quadrate articulation. Crickets were weighed to the nearest $0.1 \mathrm{mg}$ immediately before each feeding trial. Cricket live mass (CMASS) in grams can be converted to length $(L)$ in millimetres: $L=$ 26.87CMASS ${ }^{0.30}$ (Andrews and Asato 1977).

\section{Measurements of oxygen consumption}

Aerobic metabolism was measured while lizards subdued and swallowed crickets. Observations were made in an environmental chamber at $32^{\circ}-34^{\circ}$. The photoperiod corresponded to the local photoperiod in April 1982, when the experiments were conducted. Metabolism chambers, made from transparent plastic cylinders, were 8.2 or $11.3 \mathrm{~cm}$ in diameter and 2.5 or $3.7 \mathrm{~cm}$ deep. Preliminary observations showed that gluing a layer of sand to the floor of the chambers reduced the lizards' attempts to escape. We withdrew 10-mL gas samples from the chambers with syringes, removed $\mathrm{CO}_{2}$ and water vapor, and measured the fractional oxygen concentration with an Applied Electrochemistry (Sunnyvale, California, USA) S3A oxygen analyzer. A Razel Scientific (Stamford, Connecticut, USA) syringe pump was used to inject gas into the analyzer. A Houston Instruments (Austin, Texas, USA) Omniscribe recorder allowed us to determine oxygen concentration to $0.002 \%$. Rates of oxygen consumption (at STPD) were calculated using the equations of Vleck (1978).

Metabolic rates $\left(\dot{\mathrm{V}}_{2}\right.$, measured as cubic centimetres of $\mathrm{O}_{2}$ consumed per hour) at $32^{\circ}$ during rest and forced exercise had previously been determined for these lizards (Pough and Andrews 1984) as:

$$
\begin{aligned}
\text { Resting } \dot{\mathrm{V}}_{2} & =0.313 \text { (mass) }^{0.626} \\
\text { Exercise } \dot{\mathrm{V}}_{2} & =1.792 \text { (mass) }^{0.767} \text {. }
\end{aligned}
$$

We fasted lizards for $72 \mathrm{~h}$ and measured their oxygen consumption as they ate live or dead crickets. All measurements were made between 1200 and 1600 Eastern Standard Time. Oxygen consumption as a lizard struggled to subdue and swallow a cricket was measured by taking an initial gas sample at the moment the lizard seized the cricket and a second sample when the lizard protruded its tongue after the cricket disappeared into its throat, indicating that the pharyngeal packing stage of food transport had been reached (Smith 1984). This 


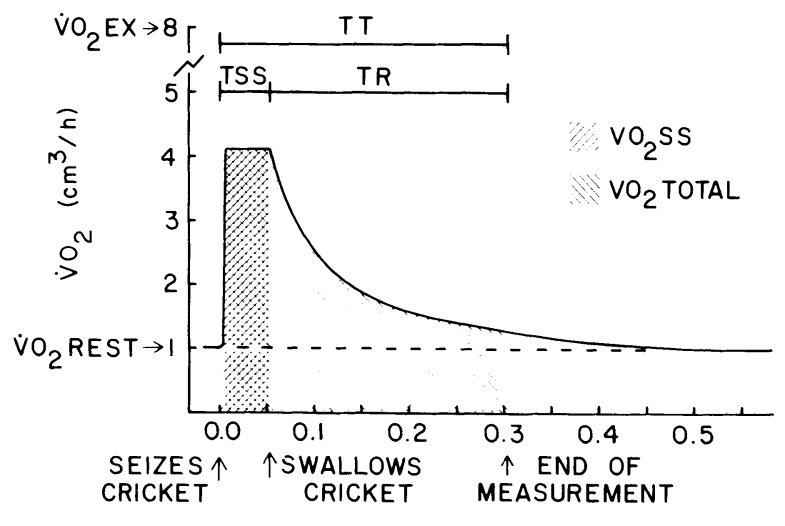

TIME (h)

Fig. 1. Pattern of oxygen consumption for a 7.1-g Chalcides ocellatus lizard eating a $0.51-\mathrm{g}$ cricket. TSS $=$ time to subdue and swallow, $\mathrm{TR}=$ recovery time, $\mathrm{TT}=$ total time, $\dot{\mathrm{V}}_{\mathrm{O}_{2}} \mathrm{REST}=$ resting rate of oxygen consumption, $\dot{\mathrm{V}}_{2} \mathrm{EX}=$ rate of oxygen consumption during forced locomotion, $\mathrm{VO}_{2} \mathrm{SS}=$ volume of oxygen consumed while subduing and swallowing cricket, $\mathrm{VO}_{2}$ TOTAL $=\mathrm{VO}_{2} \mathrm{SS}$ plus volume of oxygen consumed during the 15 -min recovery period.

interval was timed to the nearest second with a digital stopwatch. A third gas sample was drawn 15 min later to measure the lizard's oxygen consumption during recovery. Different sizes of crickets were presented to the lizards in random order.

Elevated rates of oxygen consumption continue for some time after a lizard has swallowed a cricket; the increase makes up part of the aerobic cost of feeding. To determine the time needed for a lizard to return to resting rates of oxygen consumption, we fed each of six lizards (average body mass $7.1 \mathrm{~g}$ ) a cricket (average mass $0.51 \mathrm{~g}$ ) and measured oxygen consumption during four 2 -min periods within the first $11 \mathrm{~min}$ following ingestion. The decline in rate of oxygen consumption can be described by:

$$
\dot{\mathrm{V}}_{2}=0.783 t^{-0.361} \quad\left(r^{2}=0.99\right),
$$

where $t=$ time in hours. Solution of this equation showed that oxygen consumption returned to resting rates $\left(1.0 \mathrm{~cm}^{3} / \mathrm{h}\right)$ in $0.5 \mathrm{~h}$. This means that $93 \%$ of the oxygen consumption in excess of resting metabolism associated with subduing and swallowing the crickets had occurred in the $15 \mathrm{~min}$ after swallowing (Fig. 1).

When we fed live crickets to lizards, part of the oxygen consumption we measured represented metabolism of the cricket. The oxygen consumption of a struggling cricket was determined by measuring the metabolic rates of six crickets $(0.418-0.587 \mathrm{~g})$ clasped by the thorax in a small metal clamp (an alligator clip) with the jaws of the clamp bent to maintain a 2-mm opening. The average rate of oxygen consumption by these crickets $( \pm \mathrm{SD})$ was $2.185 \pm 0.280 \mathrm{~cm}^{3} \cdot \mathrm{g}^{-1} \cdot \mathrm{h}^{-1}$. This value, multiplied by the mass of the cricket and the time from the start of the experiment until the cricket no longer made ventilatory movements, was subtracted from the oxygen consumption measured in the chamber between the first and second gas samples.

We conducted trials in which lizards ate both live crickets and crickets that had been killed by freezing. For each lizard size class, oxygen consumption by lizards eating dead crickets was slightly, but not significantly, greater than by lizards eating live crickets $(P>$ .05 , two-tailed $t$ tests, for both intercepts and slopes). Thus, our estimate of the metabolism of the live cricket was accurate. We report here only the results of trials in which lizards ate dead crickets, to avoid the potential errors introduced by estimating the metabolic rates of struggling crickets.

\section{Anaerobic metabolism}

Whole-body concentrations of lactic acid were measured for three lizards (4.9-7.8 g) at rest and for six lizards $(4.7-6.7 \mathrm{~g})$ that had just consumed large crickets $(0.52-0.67 \mathrm{~g})$. The procedure was like that for measurements of oxygen consumption: fasted lizards were placed in chambers in the environmental room $18 \mathrm{~h}$ before measurements were started. Resting lizards were tipped directly into liquid nitrogen. Fed lizards were given crickets and the oxygen consumption was measured as the lizard subdued and swallowed the cricket; as soon as the second gas sample was drawn, the lizard was dropped into liquid nitrogen.

Because the feeding behavior of Chalcides suggested that any formation of lactic acid would occur in the anterior part of the body, the frozen lizards were bisected just anterior to the pelvic girdle and the anterior and posterior portions of the lizards were homogenized separately in $10 \mathrm{~mL}$ of $1 \mathrm{~mol} / \mathrm{L}$ perchloric acid; the crickets were separated from the lizard tissue before analysis. The homogenate was centrifuged and the su-

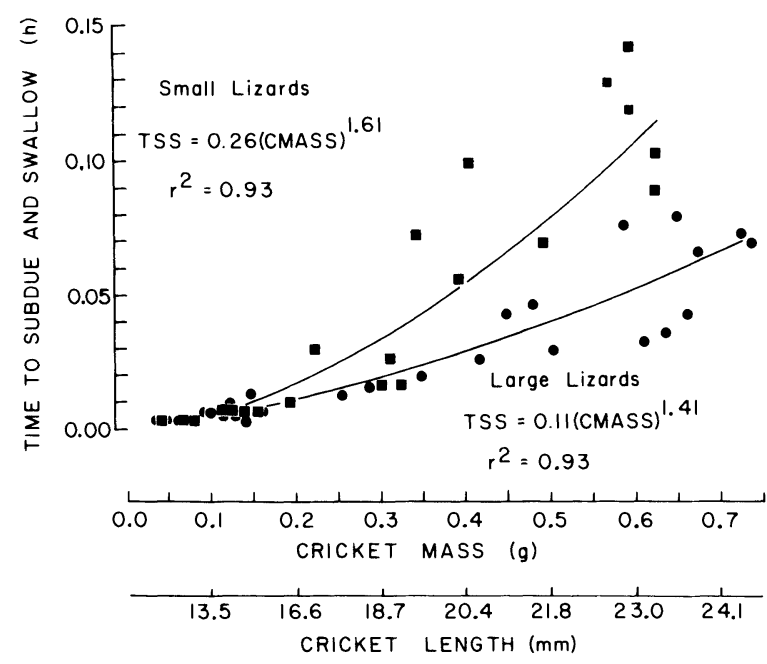

FIG. 2. Time required to subdue and swallow a cricket (TSS) as a function of cricket live mass (CMASS) and length for small $(\square)$ and large $(\bullet)$ Chalcides ocellatus lizards. (Four data points for CMASS $<0.2 \mathrm{~g}$ are obscured.) 


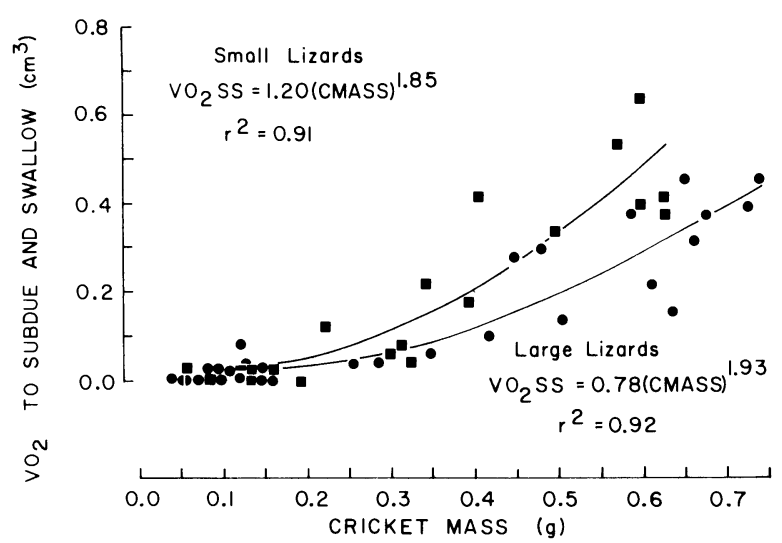

FIG. 3. Oxygen consumption during subduing and swallowing $\left(\mathrm{VO}_{2} \mathrm{SS}\right)$ as a function of cricket live mass (CMASS) for small (घ) and large (๑) Chalcides ocellatus lizards. Zero oxygen consumption values result from the fact that crickets smaller than $0.2 \mathrm{~g}$ were normally swallowed in $60 \mathrm{~s}$ or less, and our system was unable to detect oxygen consumption in those brief intervals. (Two data points for CMASS $<0.15 \mathrm{~g}$ are obscured.)

pernatant solution filtered through a Gelman fiber glass prefilter and frozen until analysis. Lactic acid concentration was measured spectrophotometrically in duplicate samples using the Sigma 826-UV technique (Sigma Chemical Company 1975). An initial measurement of absorbance was made with buffer solution, substrate, and nicotine adenine dinucleotide in the cuvette, lactate dehydrogenase was added, and a final reading was made 30 min later. Standard curves derived from solutions of known lactate concentration were prepared for each set of analyses.

Linear and nonlinear least-squares regression analyses were used to determine the relationships between variables (Ray 1982). The best fit to linear, power, and exponential functions was determined from $r^{2}$ values and the relationship giving the highest $r^{2}$ is reported. The significance of differences in slopes and intercepts was determined with two-tailed $t$ tests. Preliminary stepwise multiple regression analyses showed that the mass of the cricket explained more of the variation in dependent variables than linear measurements of cricket size. Therefore, mass of the cricket was used in all subsequent analyses rather than a linear dimension.

\section{RESULTS \\ Prey-handling behavior}

Lizards pressed crickets against the floor or wall of the metabolic chamber and immobilized them with bites on the thorax and abdomen. During this process a lizard's head and the anterior part of its trunk were raised from the substrate, and its neck was arched. The posterior part of the trunk, the hind limbs, and the tail did not appear to contribute to the process of subduing prey. Lizards paused at intervals and breathed deeply and rapidly. Most crickets were swallowed headfirst; the few exceptions were omitted from analysis. The lizards paused to breathe during the process of swallowing large crickets.

\section{Measures of cost}

The cost to a predator of subduing and swallowing prey can be assessed in units of time or energy. We measured the relationship of prey size to time, oxygen consumption (aerobic cost), and lactic acid production (anaerobic cost).

Time. - The time required for lizards to subdue and swallow prey (TSS, in hours) increased nonlinearly with increasing cricket mass (CMASS, in grams) (Fig. 2). As cricket size increased, the time required for subduing and swallowing increased faster for small than for large lizards $(P<.05$, two-tailed $t$ test for comparisons of slopes, $t=2.44, \mathrm{df}=47$ ). Thus, both small and large lizards subdued and swallowed the smallest crickets $(0.050 \mathrm{~g})$ in $\approx 8 \mathrm{~s}$, but the small and the large lizards took $7 \mathrm{~min}$ and $3 \mathrm{~min}$, respectively, to subdue and swallow large $(0.6 \mathrm{~g})$ crickets.

Aerobic cost. - Oxygen consumption (in cubic centimetres) was measured from the time that the prey was seized until it was swallowed $\left(\mathrm{VO}_{2} \mathrm{SS}\right)(\mathrm{Fig} .3)$ and until $15 \mathrm{~min}$ after it was swallowed $\left(\mathrm{VO}_{2} \mathrm{TOTAL}\right)$. Both measures of the aerobic costs of subduing and swallowing were nonlinear functions of the mass of the cricket eaten:

$$
\begin{gathered}
\mathrm{Vo}_{2} \mathrm{SS}=1.20(\mathrm{CMASS})^{1.85} \\
\left(\text { small lizards, } P<.001, r^{2}=0.91\right) \\
\mathrm{VO}_{2} \mathrm{SS}=0.78(\mathrm{CMASS})^{1.93} \\
\text { (large lizards, } P<.001, r^{2}=0.92 \text { ) }
\end{gathered}
$$

and

$$
\begin{gathered}
\mathrm{VO}_{2} \text { TOTAL }=1.50(\mathrm{CMASS})^{0.82} \\
\text { (small lizards, } P<.001, r^{2}=0.92 \text { ) } \\
\mathrm{Vo}_{2} \text { TOTAL }=1.18(\mathrm{CMASS})^{0.50} \\
\text { (large lizards, } \left.P<.001, r^{2}=0.96\right) .
\end{gathered}
$$

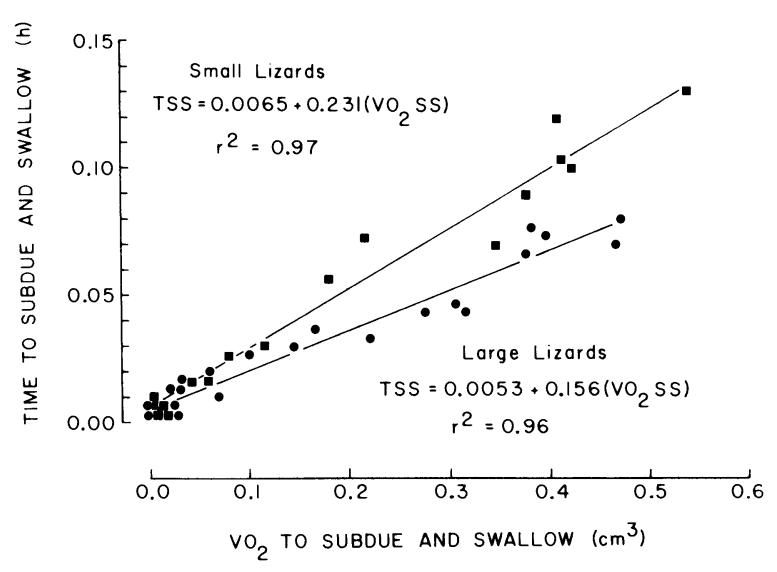

Fig. 4. Cost of subduing and swallowing crickets in units of time and energy. Time and oxygen consumption are linearly related for small $(\square)$ and large $(\bullet)$ Chalcides ocellatus lizards. (Twelve data points for $\mathrm{O}_{2}$ consumption $<0.1 \mathrm{~cm}^{3}$ are obscured.) 
$\mathrm{Vo}_{2} \mathrm{SS}$ increases more rapidly with increasing prey size than $\mathrm{VO}_{2} \mathrm{TOTAL}$; this is because as prey size increases, the aerobic cost of subduing and swallowing becomes a larger fraction of the total oxygen consumption. Net energy expenditures (oxygen consumption during subduing and swallowing less resting values) are reported in the Appendix. None of the differences in slopes and intercepts between lizard size classes for $\mathrm{VO}_{2} \mathrm{SS}$ and $\mathrm{VO}_{2}$ TOTAL were statistically significant $(P>.05, t$ tests).

Time vs. aerobic cost to subdue and swallow. - The time required to subdue and swallow (TSS) and the oxygen consumption during subduing and swallowing $\left(\mathrm{VO}_{2} \mathrm{SS}\right)$ were linearly related for both lizard size classes (Fig. 4). The slope of the regression equation was significantly greater for the small than for the large lizards $(P<.01$, two-tailed $t$ test $)$.

Anaerobic cost. - Lactic acid accumulated in the forepart of the bodies of the lizards as they subdued and swallowed crickets. Lipid from fat in the tail prevented measurement of lactic acid from the posterior portions of the lizards. Forebody lactic acid concentrations of lizards at rest averaged $0.054 \mathrm{mg} / \mathrm{g}$ (range: $0.042-0.076 \mathrm{mg} / \mathrm{g}, n=3$ ), whereas lizards that had just consumed a cricket had a lactate concentration of 0.228 $\mathrm{mg} / \mathrm{g}(0.144-0.332 \mathrm{mg} / \mathrm{g}, n=6)$.

\section{Discussion}

\section{Aerobic cost of subduing and swallowing prey}

Subduing and swallowing relatively large crickets required a high rate of aerobic energy input by the lizards (Fig. 1). The rate of oxygen uptake $\left(\mathrm{V}_{\mathrm{O}_{2}} \mathrm{SS}\right)$ while a 7.1-g lizard subdued and swallowed a 0.51 -g cricket increased four times over resting values. After the cricket was swallowed, the rate of oxygen consumption gradually dropped to resting levels. In this example, $56 \%$ of $\mathrm{VO}_{2}$ TOTAL occurred during the 15 -min recovery period. In contrast, for lizards eating the smallest crickets, the rate of oxygen consumption was not detectably elevated over resting, and the total oxygen uptake during the observation period was indistinguishable from resting oxygen consumption.

For both small and large lizards, aerobic metabolism during subduing and swallowing $\left(\mathrm{V}_{2} \mathrm{SS}\right)$ increased as a power function of cricket mass. Small lizards required slightly more energy to subdue and swallow crickets of a given size than did large lizards. The $\mathrm{VO}_{2}$ TOTAL associated with subduing and swallowing prey also increased as a power function of cricket mass, and again small lizards required slightly more energy than large lizards.

The energy required to subdue and swallow a particular prey item might become limiting if it exceeded the predator's aerobic scope (the difference between the resting rate of oxygen consumption of an organism and its maximum rate). Aerobic scope represents the potential increase in energy input available from aero- bic pathways to meet the demands of high levels of activity. A struggle that required a predator to exceed its aerobic scope would force it into substantial anaerobic metabolism. How close a Chalcides came to that point during subduing and swallowing is expressed as the increase in oxygen consumption above resting levels as a fraction of its aerobic scope. Observed fractional aerobic scopes ranged from 0.0 to 0.84 . Large crickets forced lizards to use large fractions of their aerobic scopes as

$$
\begin{gathered}
\text { Fractional scope }=0.042+0.96(\text { CMASS }) \\
\left(F_{1,47}=66.0, P<.001, r^{2}=0.57\right) .
\end{gathered}
$$

Neither the slopes nor the intercepts of the equations for small and large lizards differed $(P>.05$, two-tailed $t$ tests) and the equation for the combined data is therefore presented. The expected fractional aerobic scope for the largest crickets that were eaten $(0.7 \mathrm{~g})$ was 0.69 (Eq. 6). Crickets bigger than $0.7 \mathrm{~g}$ were not available. However, two Chalcides with masses of $2.9 \mathrm{~g}$ failed to swallow crickets with masses of 0.33 and $0.43 \mathrm{~g}$ (11 and $15 \%$ of lizard mass). In both cases, the crickets were regurgitated and dismembered before being eaten. The 0.7-g crickets used in the experiments represented 14 and $9 \%$ of the mean mass of the small and large lizards, respectively. These crickets were probably close to the largest crickets that could be swallowed whole. Thus, crickets that can be captured and swallowed whole do not stress lizards to the point at which they must exceed their aerobic scopes.

\section{Anaerobic cost of subduing and swallowing prey}

Despite the fourfold increase in average concentration of lactic acid in the forebodies of lizards after eating crickets, the energetic contribution of anaerobic pathways to the total cost of a predatory event was minor in these experiments. Using the conversion factors (1) $1 \mathrm{mg}$ lactate formed $=0.0167 \mathrm{mmol} \mathrm{ATP}$ and (2) $1 \mathrm{~cm}^{3}$ oxygen consumed $=0.290 \mathrm{mmol}$ ATP (Bennett and Licht 1972), we calculated that $92.5 \%$ of the energy input during handling and swallowing was derived from aerobic pathways. (We considered only the tissue mass and lactate concentration of the anterior portions of the lizards for these calculations. Because the average mass of the pelvis and tail was only half that of the anterior part of the body [2.0 and $4.0 \mathrm{~g}$, respectively] and the tail contains little muscle, the error introduced by omitting it is small.) The increased concentrations of lactic acid $(0.17 \mathrm{mg} / \mathrm{g})$ we found in Chalcides after they ate relatively large crickets suggest that the high rates of energy input required to handle and swallow large prey exceeded the anaerobic threshold of some muscles, and as a consequence there was an accumulation of lactic acid. Anaerobic metabolism may play a crucial role in the function of individual muscles, but anaerobic energy input seems to be a small factor in the overall energetic cost of predation. 


\section{Net energy per prey}

An important aspect of prey capture is the net energy that the predator obtains from each prey item relative to its long-term energy requirements. For each cricket eaten, the net energy per prey (NEPP) was calculated as

$$
\begin{aligned}
& \text { potential prey energy } \\
& \mathrm{NEPP}=\frac{- \text { total net aerobic cost }}{\text { daily energy requirement }} \text {, }
\end{aligned}
$$

where the potential prey energy was CMASS (live mass in grams) $\times 0.24$ (ratio of dry to live mass) $\times 24062.5$ (cricket energy density, in joules per gram dry mass) $\times$ 0.80 (assimilation efficiency), the total net aerobic cost of eating the cricket (Appendix) was [ $\mathrm{VO}_{2} \mathrm{TOTAL}$ (in cubic centimetres of $\mathrm{O}_{2}$ ) minus the resting metabolism of the lizard for both the period that it spent eating the cricket and the $15-\mathrm{min}$ recovery period (in cubic centimetres of $\mathrm{O}_{2}$ )] $\times 20.1 \mathrm{~J} / \mathrm{cm}^{3} \mathrm{O}_{2}$, and the daily energy requirement was resting metabolism for a $24-\mathrm{h}$ period $\left(6 \mathrm{~h}\right.$ at $34^{\circ}$ and $18 \mathrm{~h}$ at $\left.24^{\circ}\right) \times 20.1 \mathrm{~J} /$ $\mathrm{cm}^{3} \times 2.5$ (activity factor). The energy value of crickets is from Andrews and Asato (1977) and the 2.5 activity factor ([metabolism of a free-ranging lizard]/[metabolism of a lizard at rest in the laboratory]) is from Bennett and Nagy (1977). An assimilation efficiency of 0.80 is typical of insectivorous lizards (Andrews and Asato 1977).

For both lizard classes, NEPP (in joules per day) increased linearly with CMASS (in grams) as

$$
\begin{gathered}
\operatorname{NEPP}_{\text {(small lizards) }}=0.105+7.68(\mathrm{CMASS}) \\
\left(P<.001, r^{2}=0.98\right) \\
\mathrm{NEPP}_{\text {(large lizards) }}=-0.016+6.07(\mathrm{CMASS}) \\
\left(P<.001, r^{2}=0.98\right) .
\end{gathered}
$$

The rate of increase of NEPP with increasing CMASS was greater for small than for large lizards $(P<.05$, two-tailed $t$ test), but the intercepts were not different $(P>.05)$. The net energy gain from eating a cricket equals the daily energy requirement when NEPP $=1$. That point occurs for small and large Chalcides eating crickets of 0.116 and $0.167 \mathrm{~g}$, respectively. Crickets of this size took relatively little time to subdue and swallow: 27 and $37 \mathrm{~s}$, respectively.

On the other hand, Chalcides that ate large crickets $(0.7 \mathrm{~g})$ acquired sufficient energy for 5.5 and $4.2 \mathrm{~d}$ (small and large lizards, respectively). Crickets of this size took 7.6 and $3.5 \mathrm{~min}$ to subdue and swallow, respectively.

Thus, the energy cost of consuming prey items that a lizard is capable of swallowing whole is always very much less than the energy gained from the prey; the magnitude of NEPP increases with prey size. For example, crickets of 0.1 and $0.7 \mathrm{~g}$ have respective energy values of 462 and $3234 \mathrm{~J}$. To eat crickets of these sizes, a large Chalcides in our experiments would expend only 1 and $14 \mathrm{~J}$, respectively. Therefore, if NEPP were the only consideration, a lizard should eat all potential prey items up to the size at which it is no longer physically capable of ingesting the prey. This relationship probably applies to snakes as well (Feder and Arnold 1982, Greene 1984). For Chalcides, physical limitations rather than energy costs appear to set the upper bounds of prey that the lizards in our experiments could attack successfully. That relationship, in part, may account for the correlation between head or jaw size and dietary habits that has been reported in various studies of lizards (Schoener and Gorman 1968, Pianka 1969, Andrews 1979a).

\section{Time as a measure of cost}

The time a lizard used to subdue and swallow prey (TSS) and the oxygen consumption during subduing and swallowing $\left(\mathrm{VO}_{2} \mathrm{SS}\right)$ were highly correlated in our experiments. Thus, either could be used to estimate the aerobic energy cost of a predatory event. This assumption is embodied in many models of foraging behavior, but its usefulness is limited because estimates of energy cost based on time are probably comparable only within one type of prey. Different types of prey are likely to have different energy costs associated with subduing them. Soft-bodied prey like caterpillars and some spiders, for example, are probably easier to subdue than crickets of the same size. Armored prey like beetles may be more difficult to subdue than crickets. Thus, each type of prey would be represented by a different relationship among aerobic energy cost, time, and size.

\section{Net energy per feeding time}

A common assumption of optimal foraging models is that the optimal diet is one in which the net energy per unit feeding time is maximized (Schoener 1969, 1979, Werner et al. $1983 a, b$ ). In order to predict the optimal diet, prey are first ranked according to

$$
e / t=\frac{\begin{array}{c}
\text { potential prey energy } \\
- \text { total net aerobic cost }
\end{array}}{\text { TSS }}
$$

where $e / t$ is the net energy per unit time spent subduing and swallowing, and potential prey energy and total net aerobic cost are defined as for Eq. 7. The relationship between $e / t$ and CMASS for Chalcides is:

$$
\begin{gathered}
e / t_{\text {(small lizards) }}=105274 \cdot 10^{-0.97 \text { CMASs }} \\
\left(P<.001, r^{2}=0.88\right) \\
e / t_{\text {(large lizards) }}=102410 \cdot 10^{-0.39 \text { CMASs }} \\
\left(P<.001, r^{2}=0.88\right),
\end{gathered}
$$

where $e / t$ is expressed in joules per hour. Not surprisingly, $e / t$ decreased more rapidly with increasing CMASS for the small than for the large lizards $(P<$ $.05, t$ test). The form of these equations is a monoton- 
ically declining curve. For the Chalcides, the maximum $e / t$ is observed for the smallest crickets eaten in our experiment $(0.04 \mathrm{~g}$ or $10 \mathrm{~mm})$. If there is an ascending portion of the $e / t$ curve, it must be associated with crickets that are smaller than were used in our experiments. Thus, our data cannot be used to predict the prey size that would maximize $e / t$ for $C$. ocellatus. They do suggest however, that the prey size for which $e / t$ is maximal is less than a quarter of the mass of an item that would satisfy daily energy requirements.

For the Chalcides, the $e / t$ curve descends over the range of prey sizes eaten in our experiments. The energy cost of subduing and swallowing is trivial compared to the energy value of the prey over all prey sizes that the Chalcides can eat. Therefore, the curve descends because TSS increases faster with increasing cricket mass (slope $>1$ ) than the energy value of the cricket increases (slope $=1$ ). For those vertebrate predators that swallow their prey whole, the energy cost of subduing and swallowing prey may generally be trivial compared to the energy value of those prey (Sherry and McDade 1982, Werner et al. 1983a, Stein et al. 1984). Thus, the shape of the $e / t$ curve will be determined essentially by the shape of the TSS curve. For example, in contrast to our observations, the $e / t$ curve for redear sunfish eating snails increased monotonically with increasing prey size because the time required for subduing and swallowing increased less rapidly than did the energy value of the prey (Stein et al. 1984).

The energy cost of pursuit was obviously negligible in our study, and low costs of pursuit are probably characteristic of most lizard predators. The net cost of transport (NCT, expressed as cubic centimetres of $\mathrm{O}_{2}$ consumed per kilometre traveled) is independent of the speed of travel. For lizards

$$
\text { NCT }=3.77(\text { mass })^{0.75}
$$

(Gleeson 1979). Thus, a 5.1-g lizard could pursue a $0.125-\mathrm{g}$ cricket for $1.8 \mathrm{~km}$ before its increased energy expenditure resulting from that pursuit equalled the energy it would realize by eating the cricket. Alternatively, the lizard could chase 100 insects of that size for $1.8 \mathrm{~m}$ each and recoup its energy expenditure by catching one of them. Consequently, for small lizards like Chalcides that pursue prey over short distances, the energetic cost of pursuit is negligible. A potentially more signficant cost of pursuit is the possibility that frequent or sustained chases would require substantial anaerobic metabolism with a consequent short-term reduction in the capacity for further anaerobically sustained activity by the lizard.

\section{What is optimal prey choice for Chalcides?}

A predator that is feeding optimally should specialize on the prey item with the highest value of $e / t$ if it acquires more energy per unit time spent foraging on that one item than on that item plus items with lower values of $e / t$ (Schoener 1969, Werner et al. 1983a).
Thus, diet breadth is a function of the abundance (or rate of encounter) of each prey type, i.e., breadth increases when the low availability of highly ranked prey does not allow the predator to specialize on that item. The magnitude of $e / t$ for Chalcides, and presumably other lizards as well, is the highest at very small prey sizes. Thus, optimal foraging theory in its simplest form (Schoener 1971) predicts that if small prey are sufficiently abundant, they should be the major constituents of lizard diets.

With the exception of the few species that specialize on ants and termites (Huey et al. 1974, Pianka and Parker 1975), lizards generally acquire a large fraction of their energy intake from relatively large prey (Pianka 1969, Roughgarden 1972, Van Devender 1977, Andrews 1979a, b). Small arthropods (lengths of 1-3 mm) are the most abundant in the environment, and abundance declines monotonically towards larger sizes (Janzen and Schoener 1968, Andrews 1979a). Thus, large prey are common in lizard diets despite their low values of $e / t$ and the greater abundance of prey with higher $e / t$ values.

At least two hypotheses could explain why lizards eat large prey. If small prey are not sufficiently abundant to meet the energy demands of a particular lizard, optimal foraging theory predicts that the lizards should feed on a wide range of prey sizes. A second hypothesis, not consistent with optimal foraging theory, is that maximization of energy per unit feeding time may be biologically unimportant for lizards. Because the energy value of all prey is extremely high relative to the energy cost of pursuing, subduing, and swallowing, large items may always be eaten. This relationship is true even for prey that approach the maximum size a lizard can swallow whole, and it can probably be extended to prey that must be dismembered before being swallowed. On this basis, Feder and Arnold (1982) predicted that garter snakes should attack large prey, even if many such predatory attempts were unsuccessful.

Consideration of the absolute energy value of the prey becomes important when there is a trade-off between risk of predation and energy accrual. Eating small prey necessitates eating many times. Thus, if the risk that a lizard is detected by a predator depends on the number of times it moves to capture prey rather than the time it spends eating, large prey should be preferred. That is, such lizards may be movement minimizers. For example, the iguanid Corytophanes cristatus eats arthropods that average one-half its snout-vent length (Andrews 1979b). The large items provide a high net energy yield and minimize the number of movements that would reveal the presence of the lizard to its own predators. In general, the net effect of risk is to reduce foraging efficiency (Stein 1977, Sih 1980, Werner et al. $1983 b$, Sullivan 1984).

Are any lizards optimal foragers in the sense of maximizing energy per unit time spent foraging? To answer this question, both $e / t$ and prey abundance functions 
must be known. Our study is the first to provide sufficient information to determine $e / t$ functions. An important consequence of the trivial energy cost of pursuit, subduing, and swallowing prey by Chalcides, and presumably by other lizards as well, is that the shape of the $e / t$ function is determined by only two variables: potential prey energy and the time required for pursuit, subduing, and swallowing. Potential prey energy is readily estimated from prey mass, and the time required for pursuit, subduing, and swallowing is readily measured under field or laboratory conditions (see Sherry and McDade 1982 for an example of this approach). Prey abundance functions can be measured by a variety of techniques (Andrews 1979a, Stamps et al. 1981, Pacala and Roughgarden 1984). Thus, it should be possible to employ data collected in real communities to construct optimal foraging models for lizards. Such models could profitably be used to evaluate deviations from expected behavior in terms of risk, competition, and prey availability.

\section{ACKNOWLEDGMENTS}

We would like to thank Alan de Queiroz, Martin Feder, Robert Gatten, Jr., Raymond Huey, Yoh Iwasa, Thomas Schoener, Nathaniel Wheelwright, and David Winkler for their comments on the manuscript. Martin Feder also provided advice about experimental design. Research was supported by a small projects grant (to R. M. Andrews) from Virginia Polytechnic Institute and State University and by Federal Hatch funds (project number 412) from the New York State Agricultural Experiment Station (to F. H. Pough). Robert Fisk provided the original colony of Chalcides whose cooperative nature made our measurements possible, and Robert Gatten lent us his laboratory for lactate analyses.

\section{Literature Cited}

Andrews, R. M. 1979a. Evolution of life histories: a comparison of Anolis lizards from matched island and mainland habitats. Breviora 454:1-51.

- $1979 b$. The lizard Corytophanes cristatus: an extreme "sit-and-wait" predator. Biotropica 11:136-139.

Andrews, R. M., and T. Asato. 1977. Energy utilization of a tropical lizard. Comparative Biochemistry and Physiology A: Comparative Physiology 58:57-62.

Bennett, A. F. 1982. The energetics of reptilian activity. Pages 155-199 in C. Gans and F. H. Pough, editors. Biology of the Reptilia. Volume 13. Academic Press, London, England.

Bennett, A. F., T. T. Gleeson, and G. C. Gorman. 1981 Anaerobic metabolism in a lizard (Anolis bonairensis) under natural conditions. Physiological Zoology 54:237-241.

Bennett, A. F., and P. Licht. 1972. Anaerobic metabolism during activity in lizards. Journal of Comparative Physiology $81: 277-288$.

Bennett, A. F., and K. A. Nagy. 1977. Energy expenditure in free-ranging lizards. Ecology 58:697-700.

Feder, M. E., and S. J. Arnold. 1982. Anaerobic metabolism and behavior during predatory encounters between snakes (Thamnophis elegans) and salamanders (Plethodon jordani). Oecologia (Berlin) 53:93-97.

Gleeson, T. T. 1979. Foraging and transport costs in the Galapagos marine iguana, Amblyrhynchus cristatus. Physiological Zoology 52:549-557.

- 1982. Lactate and glycogen metabolism during and after exercise in the lizard Sceloporus occidentalis. Journal of Comparative Physiology B: Biochemical, Systemic and Environmental Physiology 147:79-84.

Greene, H. W. 1984. Feeding behavior and diet of the eastern coral snake, Micrurus fulvius. Pages 147-162 in R. A. Siegel, L. E. Hunt, J. L. Knight, L. Malaret, and N. L. Zuschlag, editors. Vertebrate ecology and systematics. Special Publication Number 10, University of Kansas Museum of Natural History, Lawrence, Kansas, USA.

Huey, R. B., E. R. Pianka, M. E. Egan, and W. L. W. Coons. 1974. Ecological shifts in sympatry: Kalahari fossorial lizards (Typhlosaurus). Ecology 55:304-316.

Janzen, D. H., and T. W. Schoener. 1968. Differences in insect abundance and diversity between wetter and drier sites during a tropical dry season. Ecology 49:96-1 10.

Pacala, S., and J. Roughgarden. 1984. Control of arthropod abundance by Anolis lizards on St. Eustatius (Netherlands Antilles). Oecologia (Berlin) 64:160-162.

Pasteur, G. 1981. A survey of the species groups of the Old World scincid genus Chalcides. Journal of Herpetology 15: $1-6$.

Pianka, E. R. 1969. Sympatry of desert lizards (Ctenotus) in Western Australia. Ecology 50:1012-1030.

Pianka, E. R., and W. S. Parker. 1975. Ecology of horned lizards: a review with special reference to Phrynosoma platyrhinos. Copeia 1975:141-162.

Pough, F. H., and R. M. Andrews. 1984. Individual and sibling-group variation in metabolism of lizards: the aerobic capacity model for the origin of endothermy. Comparative Biochemistry and Physiology A: Comparative Physiology 79:415-419.

Pough, F. H., and R. M. Andrews. 1985. Use of anaerobic metabolism by free-ranging lizards. Physiological Zoology 58:205-213.

Pough, F. H., and R. E. Gatten, Jr. 1984. The use of anaerobic metabolism by frogs in a breeding chorus. Comparative Biochemistry and Physiology A: Comparative Physiology 78:337-340.

Putnam, R. W. 1979a. The role of lactic acid accumulation in muscle fatigue of two species of anurans, Xenopus laevis and Rana pipiens. Journal of Experimental Biology 82:3551 .

- 1979b. The basis for differences in lactic acid content after activity in different species of anuran amphibians. Physiological Zoology 51:509-519.

Ray, A. A., editor. 1982. SAS user's guide: statistics, 1982 edition. SAS Institute, Cary, North Carolina, USA.

Roughgarden, J. 1972. Evolution of niche width. American Naturalist 106:683-718.

Ryan, M. J., G. A. Bartholomew, and A. S. Rand. 1983. Energetics of reproduction in a Neotropical frog, Physalaemus pustulosus. Ecology 64:1456-1462.

Schoener, T. W. 1969. Models of optimal size for solitary predators. American Naturalist 103:277-313.

. 1971. Theory of feeding strategies. Annual Review of Ecology and Systematics 2:369-404.

. 1979. Generality of the size-distance relation in models of optimal feeding. American Naturalist 114:902914.

Schoener, T. W., and G. C. Gorman. 1968. Some niche differences among three species of Lesser Antillean anoles. Ecology 49:819-830.

Sherry, T. W., and L. A. McDade. 1982. Prey selection and handling in two neotropical hover-gleaning birds. Ecology 63:1016-1028.

Sigma Chemical Company. 1975. Technical Bulletin Number 826-UV. Saint Louis, Missouri, USA.

Sih, A. 1980. Optimal behavior: can foragers balance two conflicting demands. Science 210:1041-1043.

Smith, K. K. 1984. The use of the tongue and hyoid apparatus during feeding in lizards (Ctenosaura similis and 
Tupinambis nigropunctatus). Journal of Zoology (London) 202:115-143.

Stamps, J., S. Tanaka, and V. V. Krishnan. 1981. The relationship between selectivity and food abundance in a juvenile lizard. Ecology 62:1079-1092.

Stein, R. A. 1977. Selective predation, optimal foraging, and the predator-prey interaction between fish and crayfish. Ecology 58:1237-1253.

Stein, R. A., C. G. Goodman, and E. A. Marschall. 1984. Using time and energetic measures of cost in estimating prey value for fish predators. Ecology 65:702-715.

Sullivan, K. A. 1984. The advantages of social foraging in downy woodpeckers. Animal Behaviour 32:16-22.

Taigen, T. L., S. B. Emerson, and F. H. Pough. 1982. Ecological correlates of anuran exercise physiology. Oecologia (Berlin) 52:49-56.

Taigen, T. L., and F. H. Pough. 1985. Metabolic correlates of anuran behavior. American Zoologist 25, in press.

Van Devender, T. R. 1977. Observations on the Argentine iguanid lizard Leiosaurus bellii Dumeril and Bibron (Reptilia, Lacertilia, Iguanidae). Journal of Herpetology 11:238241.

Vleck, D. 1978. Energetics of activity and growth. Dissertation. University of California at Los Angeles, Los Angeles, California, USA.

Werner, E. E., J. F. Gilliam, D. J. Hall, and G. G. Mittelbach. $1983 \mathrm{~b}$. An experimental test of the effects of predation risk on habitat use in fish. Ecology 64:1540-1548.
Werner, E. E., G. G. Mittelbach, D. J. Hall, and J. F. Gilliam. 1983a. Experimental tests of optimal habitat use in fish: the role of relative habitat profitability. Ecology 64:15251539 .

\section{APPENDIX}

The net aerobic cost of eating a cricket $\left(\mathrm{VO}_{2} \mathrm{SS}-\mathrm{NET}\right)$ was calculated as $\mathrm{VO}_{2} \mathrm{SS}$ minus the resting metabolism (Eq. 1) of the lizard for the time spent eating the cricket. The total net aerobic cost of eating a cricket $\left(\mathrm{VO}_{2}\right.$ TOTAL-NET) was calculated as $\mathrm{VO}_{2}$ TOTAL minus the resting metabolism of the lizard for the time it spent eating plus the 15-min recovery period. The resultant equations are:

$$
\begin{aligned}
& \mathrm{VO}_{2} \mathrm{SS}-\mathrm{NET}=0.95(\mathrm{CMASS})^{1.88} \\
& \text { (small lizards, } P<.001, r^{2}=0.90 \text { ) } \\
& \mathrm{VO}_{2} \mathrm{SS}-\mathrm{NET}=0.67(\mathrm{CMASS})^{2.07} \\
& \text { (large lizards, } P<.001, r^{2}=0.91 \text { ) } \\
& \mathrm{VO}_{2} \text { TOTAL-NET }=1.31(\mathrm{CMASS})^{1.27} \\
& \text { (small lizards, } P<.001, r^{2}=0.84 \text { ) } \\
& \mathrm{Vo}_{2} \text { TOTAL-NET }=1.05(\text { CMASS })^{1.14} \\
& \text { (large lizards, } P<.001, r^{2}=0.92 \text { ). }
\end{aligned}
$$

